\title{
Гальгенбергит-(Се) из щелочных пород Кондёрского массива (Хабаровский край)
}

Осипов А.С. ${ }^{1}$, Антонов А.А. ${ }^{2}$

${ }^{1}$ Санкт-Петербургский государственный университет, Санкт-Петербург, osipov.anst@yandex.ru

${ }^{2}$ Всероссийский научно-исследовательскийгеологический институт им. А.П. Карпинского, Санкт-Петербург, anthonov@yandex.ru

Аннотация. В работе представлена характеристика гальгенбергита-(Cе) $\mathrm{CaCe}_{2}\left(\mathrm{CO}_{3}\right)_{4} \cdot \mathrm{H}_{2} \mathrm{O}$, обнаруженного в составе щелочных эвдиалит-эгирин-альбитовых пород Кондёрского массива (Хабаровский край). Минерал ассоциирует с эвдиалитом, эгирином, альбитом, сепиолитом и кальцитом. Гальгнебергит-(Се) формирует оторочки в краевой части индивидов альбита мощностью до 50 мкм. Кристаллы бесцветные, полупрозрачные. Химическая формула в пересчете на 3 единицы катионов имеет вид: $\left(\mathrm{Ca}_{0.94} \mathrm{Sr}_{0.06}\right)_{1.00}\left(\mathrm{Ce}_{1.05} \mathrm{Nd}_{0.52} \mathrm{La}_{0.22} \mathrm{Pr}_{0.12} \mathrm{Sm}_{0.07} \mathrm{Gd}_{0.01} \mathrm{Y}_{0.01}\right)_{2.00}\left(\mathrm{CO}_{3}\right)_{4.00} \cdot \mathrm{H}_{2} \mathrm{O}$. Минерал близок по химическому составу к образцу гальгенбергита-(Се) из типового минералопроявления - туннеля Гальгнеберг в Австрии. Сделано предположение о кристаллизации карбоната в процессе разрушения гидратированного карбонатсодержащего аналога манганоэвдиалита под воздействием низкотемпературных гидротермальных растворов.

Ключевые слова: гальгенбергит-(Се), редкоземельные минералы, щелочные породы, Кондёрский массив, низкотемпературные гидротермальные преобразования.

\section{Galgenbergite - (Ce) from alkaline rocks of the Konder massif (Khabarovsk Krai)}

\author{
Osipov A.S. ${ }^{1}$, Antonov A.A. ${ }^{2}$ \\ ${ }^{1}$ Saint Petersburg State University, Saint Petersburg, osipov.anst@yandex.ru \\ ${ }^{2}$ All-Russian Research Geological Institute named after V.I. A.P. Karpinsky, St. Petersburg, \\ anthonov@yandex.ru
}

\begin{abstract}
This paper presents the characteristics of galgenbergite-(Ce) $\mathrm{CaCe}_{2}\left(\mathrm{CO}_{3}\right)_{4} \cdot \mathrm{H}_{2} \mathrm{O}$, from the alkaline eudialyte-aegirine-albite rocks of the Konder massif (Khabarovsk Kray). The mineral is associated with eudialyte, aegirine, albite, sepiolite, and calcite. Galgenbergite-(Ce) forms rims in the boundary parts of the albite crystals with a thickness up to $50 \mu \mathrm{m}$. The crystals are colorless, translucent. The chemical composition based on 3 units of cations is: $\left(\mathrm{Ca}_{0.94} \mathrm{Sr}_{0.06}\right)_{1.00}\left(\mathrm{Ce}_{1.05} \mathrm{Nd}_{0.52} \mathrm{La}_{0.22} \mathrm{Pr}_{0.12} \mathrm{Sm}_{0.07} \mathrm{Gd}_{0.01} \mathrm{Y}_{0.01}\right)_{2.00}\left(\mathrm{CO}_{3}\right)_{4.00} \cdot \mathrm{H}_{2} \mathrm{O}$. The mineral is similar in its chemical composition to the sample of galgenbergite-(Ce) from the type locality - Galgneberg tunnel, Austria. An assumption about the crystallization of galgenbergite-( $\mathrm{Ce})$ in the process of the hydrated carbonate-containing analog of manganoeudialyte destruction under the influence of low-temperature hydrothermal solutions was made.

Key words: galgenbergite-(Ce), REE-mineralization, alkaline rocks, Konder massif, low temperature hydrothermal transformations.

\section{Введение}

Редкий карбонат кальция и церия - гальгенбергит-(Ce) $\mathrm{CaCe}_{2}\left(\mathrm{CO}_{3}\right)_{4} \cdot \mathrm{H}_{2} \mathrm{O}$ был впервые обнаружен в 1998 году в Австрии (провинция Штирия) при проходке железнодорожного туннеля Гальгенберг (Hollerer, 1998). Минерал был встречен в небольших полостях в метаморфизованных альбитхлоритовых сланцах в ассоциации с сидеритом, анкилитом-(Сe), пиритом и кальцитом.

Кроме того, гальгенбергит-(Се) был обнаружен в Швеции (провинция Даларна) в гранитах I-типа массива Сёрвик (Lindh, 2012), в Парагвае (провинция Альто-Парагвай, щелочной комплекс Серро Боггиани) в составе нефелинового сиенита (Comin-Chiaramonti et al., 2016) и в Австралии (провинция Элерон) на месторождении Ноланс-Бор в составе фторапатитовых жильных тел, секущих вмещающие гранитогнейсы (Huston et al., 2016). На территории России гальгенбергит-(Се) обнаружен на Кольском полуострове (северо-западный фланг Лицко-Арагубского комплекса) в пег-
\end{abstract}


матоидных гранитах REE-Th-U - проявления Дикое (Kaulina et al., 2018) и на Южном Урале в составе сульфидных руд Талганского Cu-Zn месторождения (Ayupova et. al., 2019).

Нами гальгенбергит-(Се) был обнаружен в составе щелочных эвдиалит-эгирин-альбитовых пород Кондёрского массива (Хабаровский край). Это седьмая находка данного минерала в природе и третья на территории России. Данная работа посвящена минералогической характеристике кондёрского гальгенбергита-(Се).

\section{Геологическая позиция}

Кондёрский щелочно-ультраосновный массив находится в 800 км к северу от Хабаровска в междуречье р. Омня и р. Маймакан - левых притоков р. Мая. Массив известен, прежде всего, как одно из крупнейших россыпных месторождений платины.

Комплекс расположен в восточной части Алданского щита. На уровне современного эрозионного среза структура имеет в плане форму кольца диаметром до 8.5 км. Вмещающие породы представлены нижнеархейскими сканированными мраморами, кристаллическими сланцами и кварцитами, а также среднерифейскими терригенными породами (аргиллитами, алевролитами и песчаниками).

Интрузивные образования Кондёрского массива представлены двумя группами пород различного состава и возраста. Большую часть площади массива слагают раннепротерозойские мафитультрамафитовые породы. К ним относятся дуниты, формирующие шток в центральной части интрузии, клинопироксениты, образующие кольцевую оторочку мощностью 50-750 метров вокруг дунитового ядра, а также габбро и косьвиты представленные крупными дуговыми телами на периферии массива и многочисленными разноориентированными дайками в дунитах и клинопироксенитах. Менее распространены в пределах комплекса породы щелочной серии и их пегматиты. Они формируют маломощные жильные тела, секущие раннепротерозойские дуниты и клинопироксениты. Нами были отобраны образцы пегматитов нефелин-сиенитового, сиенитового и ийолитуртитового состава, а также вишневитовых и эвдиалит-эгирин-альбитовых пород. В последних был диагностирован гальгенбергит-(Се).

\section{Материалы и методы исследования}

Образцы для исследования были отобраны в 2013 г. в северной эндоконтактовой части Кондёрского массива из жилы щелочных эвдиалит-эгирин-альбитовых пород. Жила имеет субширотное простирание, видимую протяженность 7-9 метров, мощность - 3-5 метров. Вмещающие породы представлены пироксенитами.

Исследования выполнялись в аншлифах на оборудовании ресурсного центра СПбГУ «Геомодель». Изучение морфологии и химического состава проводились с использованием сканирующего электронного микроскопа Hitachi S-3400N с приставкой Oxford Instruments X-Max 20 и детектором Oxford Instruments Nordlys-HKLEBSD. Условия ЭДС-анализа: ускоряющее напряжение 20 кв, ток 1.7 нА, рабочее расстояние 10 мм. Аналитики - Власенко Н.С., Шиловских В.В.

\section{Результаты исследования и их обсуждение}

Минеральная ассоциация. Основной объем эвдиалит-эгирин-альбитовых пород слагают два главных минерала - эгирин и альбит, формирующие плотную мелкокристаллическую матрицу. В ней наблюдаются второстепенные лампрофиллит, баритолампрофиллит, микроклин и гидратированный карбонатсодержащий аналог манганоэвдиалита (Осипов и др., 2017). В составе пород диагностирован 21 акцессорный минерал (Осипов и др., 2021), большая часть из которых пространственно связана с индивидами эвдиалита, и вероятно, является продуктом химического разложения кольцевого цирконосиликата.

Одним из таких минералов является гальгенбергит-(Се), встреченный в центральной части реликтового зерна эвдиалита (рис. 1 a). Вмещающая минерал матрица выполнена массивным сепиолитом, в котором наблюдаются кристаллы эгирина и альбита, а также кальцит. Последний выполняет каверны и микротрещины в породе, формирует оторочки вокруг индивидов силикатов, а в некоторых случаях полностью замещает альбит. 

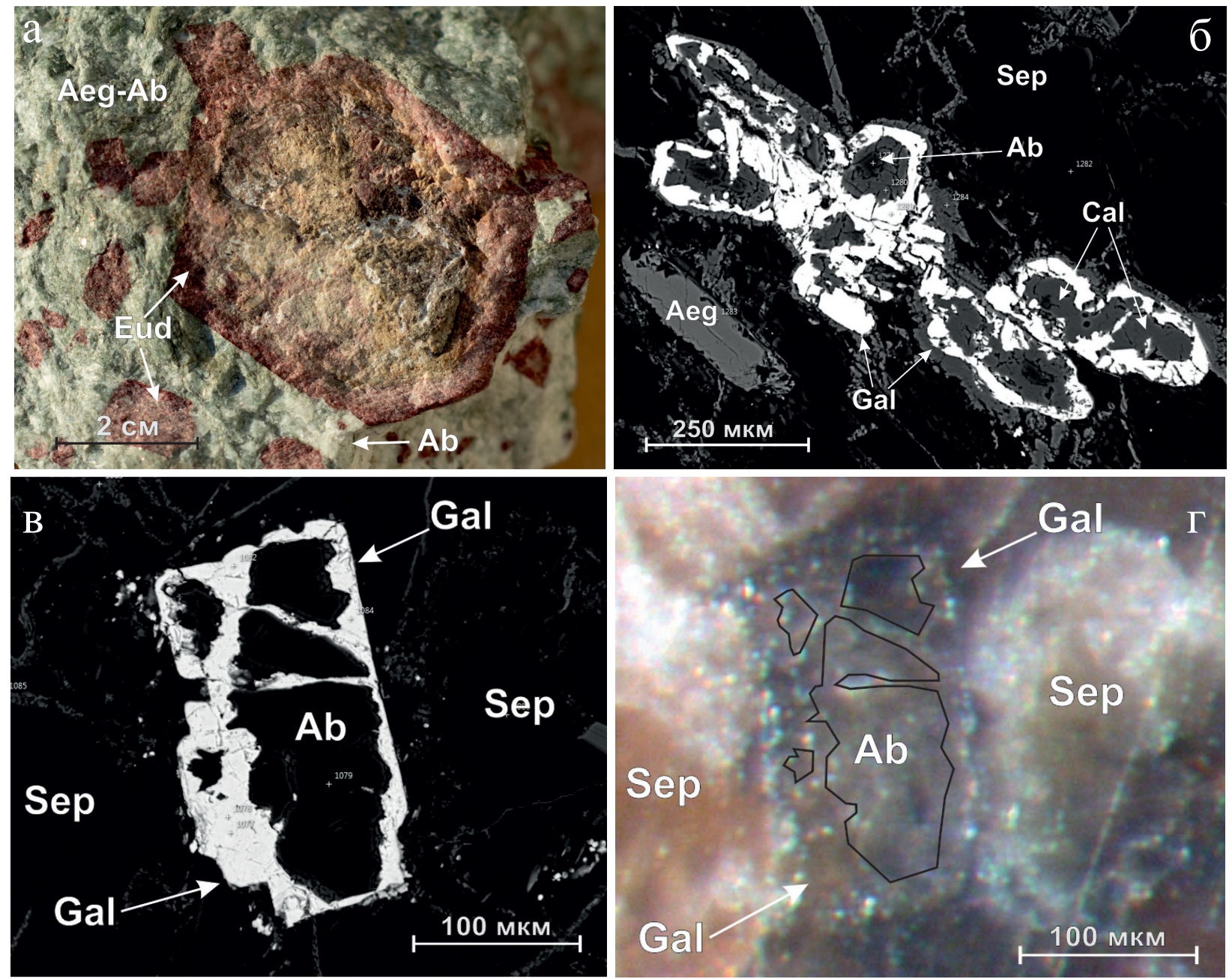

Рис. 1. Содержащие гальгенбергит-(Се) эвдиалит-эгирин-альбитовые породы Кондёрского массива. Фотографии: а - образца, б, в - аншлифов в обратно-отражённых электронах, г - аншлифа в бинокуляре.

a - общий вид породы. Крупный кристалл эвдиалита с корродированной центральной частью (Eud) в эгиринальбитовой (Aeg-Ab) матрице. б - группа зерен альбита (Ab), частично замещенных гальгенбергитом-(Cе) (Gal) (оторочки) и кальцитом (Cal) (центральная часть) в массе сепиолита (Sep). Наблюдается эгирин (Aeg). г, в - кристалл альбита (Ab) с оторочкой гальгенбергита-(Ce) (Gal) в массе сепиолита (Sep) в обратнорассеянных электронах (в) и оптике (г).

Fig. 1. Galgenbergite-(Ce)-containing eudialyte - aegirine - albite rocks of the Konder massif. Pictures of: a - rock sample, $\mathrm{b}, \mathrm{c}$ - polished sections in back-scattered electrons, $\mathrm{d}$ - polished sections in optics.

a - a general view of the rock. A large eudialyte crystal with a corroded central part (Eud) in the aegirine-albite (Aeg-Ab) matrix. $b$ - albite $(\mathrm{Ab})$ grains group partially replaced by galgenbergite-(Ce) (in the edges) and calcite (Cal) (in the central part) in the sepiolite (Sep) mass. Aegirine (Aeg) is also observed. c, d - an albite (Ab) crystal with a galgenbergite-(Ce) (Gal) rim in the sepiolite (Sep) mass in backscattered electrons (b) and optics (d).

Морфология. Гальгенбергит-(Се) образует ксеноморфные выделения, как правило формируя оторочки в краевой части зерен альбита (рис. 1 в, г). При этом сохраняется первичная морфология кристаллов плагиоклаза. Размеры оторочек варьирует от 10 до 50 мкм по ширине и до 200 мкм по удлинению. В некоторых случаях в формировании псевдоморфоз по альбиту участвует также кальцит, реликты силиката при этом наблюдаются лишь в центральной части таких агрегатов (рис. 1 б). При этом замещение альбита кальцитом, судя по всему, происходит несколько позднее кристаллизации гальнебергита-(Се). В единичных случаях гальгенбергит-(Се) также выполняет мелкие (до 5-10 мкм) каверны в массе сепиолита на границе с кристаллами альбита и эгирина. В аншлифе гальгенбергит-(Се) прозрачный, практически бесцветный. 
Таблица 1. Химический состав (масс.\%) и коэффициенты в химической формуле гальгенбергита-(Се).

Table 1. Chemical composition (wt.\%) and formula coefficients of galgenbergite-(Ce).

\begin{tabular}{|c|c|c|c|c|c|c|c|c|c|c|c|c|c|}
\hline \multirow{4}{*}{ 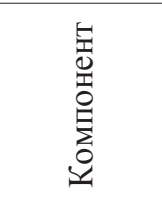 } & \multirow{4}{*}{ 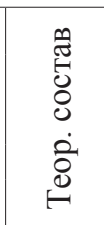 } & \multicolumn{12}{|c|}{ Место отбора } \\
\hline & & \multicolumn{6}{|c|}{ Кондёрский массивㄹ (Россия) } & \multirow{2}{*}{\multicolumn{3}{|c|}{$\begin{array}{c}\text { туннель Гальгенберг } \\
(\text { Австрия) }\end{array}$}} & \multicolumn{3}{|c|}{$\begin{array}{c}\text { массив Серро Богги } \\
\text { ани (Парагвай) }\end{array}$} \\
\hline & & \multicolumn{6}{|c|}{$\mathrm{n}=5$} & & & & & $\mathrm{n}=2$ & \\
\hline & & 1 & 2 & 3 & 4 & 5 & $\bar{X}$ & $\bar{X}$ & Min & Max & 1 & 2 & $\bar{X}$ \\
\hline $\mathrm{Al}_{2} \mathrm{O}_{2}$ & & & & & & & & & & & 0.48 & 1.20 & $0.8 \overline{4}$ \\
\hline $\mathrm{Y}_{2} \mathrm{O}_{3}$ & & & & & & 1.11 & 0.22 & & & & 0.05 & 0.01 & 0.03 \\
\hline $\mathrm{La}_{2} \mathrm{O}_{3}$ & & 6.06 & 5.54 & 5.57 & 6.28 & 4.67 & 5.62 & 11.70 & 11.07 & 12.36 & 24.82 & 26.88 & 25.85 \\
\hline $\mathrm{Ce}_{2}^{2} \mathrm{O}_{3}^{3}$ & 56.74 & 28.53 & 28.76 & 25.40 & 26.62 & 24.13 & 26.69 & 28.95 & 28.46 & 29.54 & 22.53 & 23.86 & 23.20 \\
\hline $\mathrm{Pr}_{2} \mathrm{O}_{3}^{2}$ & & 2.77 & 2.88 & 3.10 & 3.38 & 3.07 & 3.04 & 3.48 & 3.12 & 3.76 & 1.19 & 1.17 & 1.18 \\
\hline $\mathrm{Nd}_{2}^{2} \mathrm{O}_{3}$ & & 12.41 & 12.11 & 14.21 & 14.25 & 15.01 & 13.60 & 11.86 & 11.04 & 12.73 & 3.05 & 2.88 & 2.97 \\
\hline $\mathrm{Sm}_{2} \mathrm{O}_{3}$ & & 1.36 & 1.50 & 1.90 & 1.88 & 2.31 & 1.79 & & & & 0.37 & 0.27 & 0.32 \\
\hline $\mathrm{Gd}_{2}^{2} \mathrm{O}_{3}^{3}$ & & & 0.74 & & & & 0.15 & & & & & & \\
\hline $\mathrm{ThO2}$ & & & & & & & & & & & 0.10 & 0.45 & 0.28 \\
\hline $\mathrm{UO} 2$ & & & & & & & & & & & 0.06 & 0.02 & 0.04 \\
\hline $\mathrm{Fe}_{2} \mathrm{O}_{3}$ & & & & & & & & & & & 0.67 & 0.93 & 0.80 \\
\hline $\mathrm{MnO}^{3}$ & & & & & & & & & & & 0.07 & & 0.04 \\
\hline $\mathrm{SrO}$ & & 0.84 & 0.67 & 0.81 & 1.30 & 0.93 & 0.91 & & & & 6.75 & 2.44 & 4.60 \\
\hline $\mathrm{CaO}$ & 9.7 & 8.45 & 7.76 & 8.33 & 7.56 & 8.59 & 8.14 & 9.49 & 8.86 & 10.20 & 6.10 & 6.28 & 6.19 \\
\hline $\mathrm{Na}_{2} \mathrm{O}$ & & & & & & & & & & & 0.22 & 0.69 & 0.46 \\
\hline $\mathrm{K}_{2} \mathrm{O}$ & & & & & & & & & & & & 0.05 & 0.03 \\
\hline $\mathrm{F}^{2}$ & & & & & & & & & & & 0.93 & 0.92 & 0.93 \\
\hline $\mathrm{Cl}$ & & & & & & & & & & & & 0.01 & 0.01 \\
\hline$-\mathrm{O}=\mathrm{F} . \mathrm{Cl}$ & & & & & & & & & & & 0.39 & 0.39 & 0.39 \\
\hline $\mathrm{CO}_{2}$ calc* & 30.44 & 27.40 & 26.92 & 26.88 & 27.39 & 27.37 & 27.19 & 30.00 & & & 28.96 & 30.07 & 29.52 \\
\hline $\mathrm{H}_{2} \mathrm{O}$ calc* & 3.12 & 2.83 & 2.80 & 2.78 & 2.86 & 2.81 & 2.81 & 3.07 & & & 3.07 & 3.13 & 3.10 \\
\hline Total & 100.00 & 90.65 & 89.68 & 88.98 & 91.51 & 90.00 & 90.16 & 98.55 & & & 99.42 & 101.26 & 100.3 \\
\hline
\end{tabular}

Коэффициенты в кристаллохимической формуле, рассчитанные на 3 единицы суммы катионов

\begin{tabular}{|l|c|c|c|c|c|c|c|c|c|c|c|c|c|}
\hline $\mathrm{Al}$ & & & & & & & & & & & 0.05 & 0.13 & 0.09 \\
\hline $\mathrm{Y}$ & & & & & & 0.06 & 0.01 & & & & $<0.01$ & $<0.01$ & $<0.01$ \\
\hline $\mathrm{La}$ & & 0.24 & 0.22 & 0.22 & 0.25 & 0.18 & 0.22 & 0.42 & & & 0.88 & 0.93 & 0.91 \\
\hline $\mathrm{Ce}$ & 2.00 & 1.11 & 1.15 & 1.01 & 1.05 & 0.94 & 1.05 & 1.04 & & & 0.80 & 0.82 & 0.81 \\
\hline $\mathrm{Pr}$ & & 0.11 & 0.11 & 0.12 & 0.13 & 0.12 & 0.12 & 0.12 & & & 0.04 & 0.04 & 0.04 \\
\hline $\mathrm{Nd}$ & & 0.47 & 0.47 & 0.55 & 0.55 & 0.57 & 0.52 & 0.42 & & & 0.10 & 0.10 & 0.10 \\
\hline $\mathrm{Sm}$ & & 0.05 & 0.06 & 0.07 & 0.07 & 0.08 & 0.07 & & & & 0.01 & 0.01 & 0.01 \\
\hline $\mathrm{Gd}$ & & & 0.03 & & & & 0.01 & & & & & & \\
\hline $\mathrm{Th}$ & & & & & & & & & & & 0.00 & 0.01 & 0.01 \\
\hline $\mathrm{U}$ & & & & & & & & & & & $<0.01$ & $<0.01$ & $<0.01$ \\
\hline $\mathrm{Fe}$ & & & & & & & & & & & 0.05 & 0.07 & 0.06 \\
\hline $\mathrm{Mn}$ & & & & & & & & & & & 0.01 & & $<0.01$ \\
\hline $\mathrm{Sr}$ & & 0.05 & 0.04 & 0.05 & 0.08 & 0.06 & 0.06 & & & & 0.38 & 0.13 & 0.25 \\
\hline $\mathrm{Ca}$ & 1.00 & 0.97 & 0.91 & 0.97 & 0.87 & 0.98 & 0.94 & 1.00 & & & 0.63 & 0.63 & 0.63 \\
\hline $\mathrm{Na}$ & & & & & & & & & & & 0.04 & 0.13 & 0.08 \\
\hline $\mathrm{K}$ & & & & & & & & & & & & 0.01 & $<0.01$ \\
\hline $\mathrm{F}$ & & & & & & & & & & & 0.28 & 0.27 & 0.28 \\
\hline $\mathrm{Cl}$ & & & & & & & & & & & & $<0.01$ & $<0.01$ \\
\hline $\mathrm{C}$ & 4.00 & 3.99 & 4.02 & 3.99 & 4.02 & 3.98 & 4.00 & 4.00 & & & 3.81 & 3.85 & 3.83 \\
\hline $\mathrm{O}$ & 12.00 & 11.97 & 12.07 & 11.97 & 12.07 & 11.94 & 12.01 & 12.00 & & & 11.44 & 11.56 & 11.50 \\
\hline
\end{tabular}

Примечания к таблице: ${ }^{1}$ - наши данные $\left(1,2,3,4,5\right.$ - исходные анализы), ${ }^{2}$ - данные Walter et al, $2013 ;{ }^{3}$ - данные Comin-Chiaramonti et al, 2016; пустые ячейки - содержания элемента ниже порога обнаружения; $\mathrm{n}$ - число анализов для каждого источника; $\bar{X} \bar{X}$, Min, Max - среднее, минимальное и максимальное значение для группы анализов.

Химический состав. Химический состав гальгенбергита-(Се) достаточно постоянен (табл. 1). Содержания главных элементов варьируют в следующих пределах (масс. \%): $\mathrm{CaO} 7.56-8.59$ (в среднем 8.14), $\mathrm{Ce}_{2} \mathrm{O}_{3} 24.13-28.53$ (в среднем 26.69). Основные примесные компоненты (масс. \%) 
- $\mathrm{Nd}_{2} \mathrm{O}_{3}$ 12.11-15.01 (в среднем 13.60), $\mathrm{La}_{2} \mathrm{O}_{3} 4.67-6.28$ (в среднем 5.62), $\operatorname{Pr}_{2} \mathrm{O}_{3} 2.77-3.38$ (в среднем 3.04), $\mathrm{Sm}_{2} \mathrm{O}_{3}$ 1.36-2.31 (в среднем 1.79), $\mathrm{SrO}$ 0.67-1.30 (в среднем 0.91). В единичных случая отмечены $\mathrm{Y}_{2} \mathrm{O}_{3}$ - до 1.11 масс. \% и $\mathrm{Gd}_{2} \mathrm{O}_{3}$ - до 0.74 масс. \%. Расчётные содержания углерода и воды составляют (масс. \%): $\mathrm{CO}_{2 \text { calc* }} 26.88-27.40$ (в среднем 27.19), $\mathrm{H}_{2} \mathrm{O}_{\text {calc* }} 2.78-2.86$ (в среднем 2.81). Расчетное соотношение $\sum(R E E+Y) / \sum(C a+B a)$, позволившее диагностировать минерал именно как гальгнебергит-(Се), всегда близко или равняется 2. Рассчитанная по средним содержаниям элементов на 3 единицы катионов эмпирическая формула минерала имеет вид: $\left(\mathrm{Ca}_{0.94} \mathrm{Sr}_{0.06}\right)_{1.00}\left(\mathrm{Ce}_{1.05} \mathrm{Nd}_{0.52} \mathrm{La}_{0.22} \mathrm{Pr}_{0.12} \mathrm{Sm}_{0.07} \mathrm{Gd}_{0.01} \mathrm{Y}_{0.01}\right)_{2.00}\left(\mathrm{CO}_{3}\right)_{4.00} \cdot \mathrm{H}_{2} \mathrm{O}$. Полученные данные хорошо согласуются по стехиометрии с теоретической формулой гальгенбергита-(Се).

Полученные нами данные близки к теоретическому составу, а также составу минерала из Австрии. Основное отличие заключается в незначительной примеси стронция в составе образца из массива Кондёр. В то же время, составы гальгнебрегита-(Се) из Парагвая отличаются существенной примесью стронция - до 0.38 формульных коэффициентов.

По содержанию РЗЭ исследуемый минерал схож с образцом из туннеля Гальгенберг. Основное их отличие заключается в соотношении $\mathrm{Nd} / \mathrm{La}$, которое выше в образце из Кондёрского массива (2.34 против 1), а также незначительной примеси самария, гадолиния и иттрия, присутствующей в нем. При этом образец из Серро Боггиани отличается принципиально иным соотношением REE содержание лантана несколько выше содержания церия, остальные элементы присутствуют в незначительном количестве. Это дает формальный повод отнести данный минерал к La-доминантной разновидности гальгенбергита-(Се). В то же время, состав полученный авторами (Comin-Chiaramonti et al., 2016) отличается большим количеством других примесей, таких как $\mathrm{Al}, \mathrm{Th}, \mathrm{U}, \mathrm{Fe}, \mathrm{Mn}, \mathrm{Na}, \mathrm{K}$, а также $\mathrm{F}$ и $\mathrm{Cl}$, что может свидетельствовать о некоторой ошибке анализа. Данное предположение объясняет заниженные содержания углерода в расчетной формуле минерала - 3.83 ф.к.

\section{Заключение}

Кондёрский массив - седьмое известное проявление гальгенбергита-(Cе) в мире и третье - на территории России. При этом различные находки минерала сделаны в контрастных по минералогопетрографическим характеристикам объектах, что свидетельствует об отсутствии приуроченности минерала к какому-либо определённому типу материнских горных пород. Обнаруженный нами карбонат по химическому составу близок к образцу из типового проявления - туннеля Гальгенберг (Австрия).

Морфология и минеральная ассоциация гальгенбергита-(Се) указывают на его принадлежность к поздним этапам формирования пород. Это подтверждает выводы, полученные в предшествующих нашему исследованиях (Hollerer, 1998; Lindh, 2012; Comin-Chiaramonti et al., 2016; Kaulina et al., 2018). При этом источником вещества для формирования исследуемого карбоната, вероятно, послужило разрушение гидратированного карбонатсодержащего аналога манганоэвдиалита под воздействием низкотемпературных гидротермальных растворов.

\section{Благодарности}

Авторы выражают благодарность сотрудникам кафедры минералогии СПбГУ, в частности профессору А.И. Брусницыну за ценные рекомендации и комментарии к данной работе, а также сотрудникам РЦ СПбГУ «Геомодель» Н.С. Власенко и В.В. Шиловских за помощь в анализе химических составов минералов.

Работа выполнена при поддержке гранта РФФИ №19-35-90067. Исследования выполнены с использованием аналитических возможностей ресурсных центров Санкт-Петербургского государственного университета «Геомодель», «Рентгенодифракционные методы исследования».

\section{Литература}

1. Булах А.Г., Золотарёв А.А., Кривовичев В.Г. Структура, изоморфизм, формулы, классификация минералов СПб. Изд-во: С.-Петерб. ун-та. 2014. 133 с. 
2. Гурович В.Г., Емельяненко Е.П., Землянухин В.Н., Каретников А.С., Квасов А.И., Лазаренков В.Г., Малич К.Н., Мочалов А.Г., Приходько В.С., Степашко А.А. Геология, петрология и рудоносность Кондерского массива. М. Изд-во: Наука. 1994. 176 с.

3. Осипов А.С., Антонов А.А., Паникоровский Т.Л., Золотарёв-мл. А.А. Гидратированный карбонатсодержащий аналог манганоэвдиалита из щелочных пород Кондёрского массива,Хабаровский край // Записки РМО. 2017. Т. 146. №. 4. С. 78-93.

4. Петрология и платиноносность кольцевых щелочно-ультраосновных комплексов. Ред. И.Я. Некрасов и Н.П. Лаверов. М. Изд-во: Наука. 1994. 381 с.

5. Осипов А.С., Антонов А.А., Бочаров В.Н., Власенко Н.С. Стронадельфит из щелочных пород Кондёрского массива (Хабаровский край) // Записки РМО. 2021. Т. 152. №. 2.

6. Ayupova N.R., Maslennikov V.V., Filippova K.A. REE Geochemistry and Mineralogy in Ores of the Talgan $\mathrm{Cu}-\mathrm{Zn}$ Massive Sulfide Deposit, Southern Urals // Doklady Earth Sciences. 2019. V. 487/2. P. 973-975. DOI: $10.1134 / \mathrm{S} 1028334 \mathrm{X} 19080233$.

7. Comin-Chiaramonti P., Renzulli A., Ridolfi F., Gaston E.R. Enrich G. E.R., Gomes C.B., De Min A., Azzone R.G., Ruberti E. Late-stage magmatic to deuteric/metasomatic accessory minerals from the Cerro Boggiani agpaitic complex (Alto Paraguay Alkaline Province) // Journal of South American Earth Sciences. 2016. V. 71. P. 248-261. DOI:10.1016/j.jsames.2016.08.003.

8. Hollerer, C.E. $\mathrm{Ca}(\mathrm{REE})_{2}\left(\mathrm{CO}_{3}\right)_{4} \cdot \mathrm{H}_{2} \mathrm{O}$, a new mineral from Steiermark, Austria // Mitteilungen der Österreichschen Mineralogischen Gesellschaft. 1998. V. 143. P. 200-201.

9. Huston D.L., Maas R., Cross A.J., Hussey K.J., Mernagh T.P., Fraser G., Champion D.C. The Nolans Bore rare-earth element-phosphorus-uranium mineral system: geology, origin and post-depositional modifications // Miner Deposita. 2016. V. 51. P. 797-822. DOI:10.1007/s00126-015-0631-y.

10. Kaulina T.V., Kalinin A.A., Il'chenko V.L., Gannibal M.A., Avedisyan A.A., Elizarov D.V., Nerovich L.I., Nitkina E.A. Age and Formation Conditions of U Mineralization in the Litsa Area and the Salla-Kuolajarvi Zone (Kola Region, Russia) // Minerals. 2018. V. 563. N. 8. DOI:10.3390/min8120563.

11. Lindh A., Minute-sized crystals of HFSE minerals in evolved, fluorite-bearing granite, an example from the Sorvik granite, central Sweden // A Scandinavian Journal of Earth Sciences. 2012. V. 134. P. $283-294$. DOI:10.1080/11035897.2012.755707.

12. Osipov A.S., Antonov A.A., Panikorovskii T.L., Zolotarevjr A.A. Hydrated $\mathrm{CO}_{3}$-Bearing Analog of Manganoeudialyte from Alkali Pegmatites of the Konder Pluton, Khabarovsk Krai. Zapiski RMO. 2017. V. 126. N. 4. P. 78-93 (in Russian, English translation: Geol. Ore Deposits. 2018. V. 60. N.8. P. 1-10). DOI:10.1134/S1075701518080056.

13. Walter F., Bojar H.-P., Hollerer C.E., Mereiter K. The crystal structure of galgenbergite-(Ce), $\mathrm{CaCe}_{2}\left(\mathrm{CO}_{3}\right)_{4} \cdot \mathrm{H}_{2} \mathrm{O}$ // Miner. Petrol. 2013. V. 107. P. 189-199. DOI:10.1007/s00710-012-0246-2. 